\title{
A CRIANÇA E O ADOLESCENTE COMO SUJEITO DE DIREITOS HUMANOS
}

\author{
IHANDARA PROENÇA LIMA \\ MIRIAN CELIA CASTELLAIN GUEBERT
}

\begin{abstract}
RESUMO - O presente trabalho aborda a temática relacionada ao sujeito de direitos humanos, concernente à crianças e adolescentes. $O$ texto tem como problemática a compreensão sobre crianças e adolescentes sob o aspecto de sujeito de direitos, que conquistado recentemente na história brasileira, bem como as consequências para a elaboração de políticas públicas para preservação de seus interesses. Nesse contexto, busca-se apresentar uma construção histórica e legislativa sobre a proteção desse grupo populacional; a concepção de cidadania e a importância da educação como direito humano. Ainda que se vislumbre avanços sociais e políticos, imprescindível que se dê permanência a construção e efetivação dos direitos relativos às crianças e adolescentes.
\end{abstract}

PALAVRAS-CHAVE - Educação; Cidadania; Direitos Humanos.

\section{INTRODUÇÃO}

Delinear os conceitos sobre sujeito de direitos, especificamente o sujeito tutelado pelos direitos humanos representa a desconstrução do sujeito contemplado epistemologicamente pelas cientificidades e técnicas da Idade Moderna e promover a sua análise o aspecto crítico.

As crianças e os adolescentes também tiveram sua compreensão como sujeito de direitos a partir de sua racionalidade. No entanto, por se tratarem de seres humanos em potencial desenvolvimento, foram encontrados obstáculos na promoção e permanência de seus direitos. Contudo, já não é hegemônica essa compreensão no contexto das políticas públicas atuais.

Entretanto, como grupo populacional vulnerável e por tratar a matéria de direitos humanos, proveniente de lutas e conquistas históricas, necessário traçar a construção da criança e adolescente como sujeito de direito, a fim de garantir e tornar eficiente a proteção preconizada pelas declarações, constituições e legislações.

Ainda, tratar a cidadania e o direito à educação torna evidente a criança e ao adolescente como sujeitos de direitos.

\section{CONSTRUÇÃO HISTÓRICA E LEGISLATIVA DA CRIANÇA E ADOLESCENTE COMO SUJEITO DE DIREITOS NO BRASIL}

Não obstante se vislumbre vasta legislação de proteção à criança e ao adolescente no país, especialmente no que tange à promulgação recente da Lei n ${ }^{\circ} 13.431$ de 4 de abril de 2017 , a qual estabelece o sistema de garantia de direitos da criança $\mathrm{e}$ do adolescente vítima ou testemunha de violência e promove alterações ao Estatuto da Criança e do Adolescente, é recente, historicamente, o tratamento desses indivíduos como sujeitos de direitos.

Esse grupo populacional era tratado com diferenciação, pois relativizava a sua condição de sujeito de plenos direitos.

Entretanto, são indivíduos que necessitam, de cuidados específicos, pois estão em processo de desenvolvimento físico, cognitivo, psíquico e mental, inaptos, em muitas situações, para se expressar ou falar por si próprio.

\section{A. SUJEITO DE DIREITOS}

A afirmação de direitos humanos de crianças e adolescentes pauta a discussão sobre a discriminação fundada na idade para denegação de direitos a essas pessoas. Com a promulgação da Constituição Cidadã e a força dos movimentos sociais no Brasil, reconhece-se o protagonismo de crianças e adolescentes e da subjetividade desses indivíduos.

Nesse contexto, promove-se medidas apropriadas a eles para fazer postulações, cobranças de responsabilidade, oportunidade de expressão de suas opiniões. Como pontua Carbonari ( [8], p. 177) $\mathrm{O}$ sujeito de direitos não é uma abstração formal. É uma construção relacional; é intersubjetividade que se constrói na presença do outro e tendo a alteridade como presença. (...). Os direitos, assim como o sujeito de direitos, não nascem desde fora da relação; nascem do âmago do ser com os outros. Nascem do chão duro das interações conflituosas que marcam a convivência. Mais do que para regular, servem para gerar possibilidades emancipatórias.

Ressalta-se que o sujeito de direitos humanos, em sua pluridimensionalidade, atende às propostas da cultura dos direitos, em que são aspectos do sujeito a sua singularidade, particularidade e universalidade. 
Dessa forma, cada sujeito de direito é singular, está inserido em uma situação concreta, histórica, na qual a sua identidade será construída em ambientes multifacetados.

Assim, a universalidade do sujeito de direitos humanos, consoante Carbonari (2007, p. 181), exige atitudes de corresponsabilidade, compromisso, cooperação e cuidado. É importante observar que o reconhecimento de direitos das crianças e adolescentes perpassam desde a mais tenra idade, ainda quando questões relativas à educação estão inseridas no contexto familiar. Como salienta Martins [5], "O Estado pode e deve concorrer para a educação, mas como organização técnica do poder a serviço da família (...) A sociedade reflete apenas o nível de moralidade cívica que na família existe".

É imprescindível que para o desenvolvimento das crianças, os pais propiciem um ambiente de afeto e segurança.

\section{B. DECLARAÇÕES INTERNACIONAIS E O ORDENAMENTO JURÍDICO BRASILEIRO}

A concepção sobre a criança e adolescente como sujeito de direitos está diretamente ligada a construção do reconhecimento desses indivíduos como sujeito dentro das declarações internacionais. Assim, importante ressaltar o conteúdo e trazer ao debate as definições de declarações internacionais a partir do século XX. A Declaração de Genebra, aprovada em 26 de setembro de 1924 pela Assembleia da então Liga das Nações, tem sua relevância enquanto primeiro documento internacional de proteção das crianças, em que pese não as considerar sujeitos de direito. Destaca-se elementos de proteção como o recebimento dos meios necessário para o desenvolvimento normal; indivíduos que devem ser priorizados no recebimento de socorro em tempo de dificuldade; possibilidade de ter sustento; proteção de toda forma de exploração; ter educação de modo que seu talento possa ajudar outras pessoas.

A Declaração Universal dos Direitos Humanos adotada pela Organização das Nações Unidas em 10 de dezembro de 1948 juntamente com a Convenção sobre os Direitos da Criança e do Adolescente de 1989 expandiram o conteúdo do direito internacional no que tange aos direitos humanos.

Saliente-se que o conteúdo do Artigo $1^{\circ}$ da Declaração Universal dos Direitos Humanos (Assembleia Geral da ONU, 1948) [1] expressa que "todos os seres humanos nascem livres e iguais em dignidade e em direitos. Dotados de razão e de consciência, devem agir uns para com os outros em espírito de fraternidade".

Belli [2] ressalta que, a Declaração Universal dos Direitos Humanos não apenas lançou as bases do atual sistema de tratados vinculantes de direitos humanos, mas, exibindo considerável força moral, foi considerada padrão suficiente para a atuação dos órgãos extraconvencionais de monitoramento instituídos a partir dos anos de 1960 pela CDH.

$\mathrm{O}$ texto da Declaração Universal expressa a consagração de direitos civis, políticos, econômico, sociais e culturais.

No entanto, na menção sobre os seres humanos dotados de razão e consciência, tem-se que a influência da compreensão sobre sujeito de direito sob aspecto do pensamento da mo- dernidade, influenciado pelos paradigmas de uma civilização técnico-científica, numa compreensão do indivíduo como abstração formal, reduzindo-o à capacidade do pensar.

Justifica-se a ética e a dignidade humana como centralidade dos direitos humanos, desafiadas pelo enfrentamento do modelo de racionalidade (CARBONARI, 2007, p. 173).

A Constituição Federal Brasileira de 1988 [7] reconhece o protagonismo das crianças e adolescentes, isto é, como sujeitos de direito, principalmente quando trata da criança e do adolescente no capítulo VII, do título VIII sobre a Ordem Social.

Verifica-se do artigo 227 do texto constitucional (BRASÍLIA, 1988) que "é dever da família, da sociedade e do Estado assegurar à criança, ao adolescente e ao jovem, com absoluta prioridade, o direito à vida, à saúde, à alimentação, à educação, ao lazer, à profissionalização, à cultura, à dignidade, ao respeito, à liberdade e à convivência familiar e comunitária, além de colocá-los a salvo de toda forma de negligência, discriminação, exploração, violência, crueldade e opressão. ,

Anteriormente, na história do Brasil, no período colonial, crianças, assim como mulheres, estavam sob jurisdição privada dos homens e não tinham acesso à justiça ( [3], p. 14).

A Constituição Cidadã traz a consolidação do sistema democrático e o comprometimento com a cidadania a toda a população.

Ainda, ressalta-se que o Estatuto da Criança e do Adolescente, legislação infraconstitucional da década de 1990, dispõe sobre a proteção integral à criança e ao adolescente, com a primazia de que esses indivíduos devem usufruir de todos os direitos fundamentais inerentes à própria pessoa humana.

\section{O DIREITO HUMANO À EDUCAÇÃO E CIDADANIA}

Ao longo da história, observa-se que a educação já foi incumbência da Igreja e dos pais, em um contexto social que nem todos tinham esse direito.

A legislação educacional no Brasil, inicia a partir da Constituição Imperial de 1824, momento de reconhecimento formal de um direito subjetivo dos cidadãos, porém não obrigação efetiva do Estado.

Verifica-se que o direito à educação não se consolidou de início por consequência de reinvindicações sociais organizadas, mas para atender reclamos dos liberais de Portugal.

Destaca-se que a Constituição de 1891 carrega fator histórico de relevância quanto à educação, pois foi o momento em que se deu o rompimento com a Igreja Católica, que não mais influencia no sistema de ensino, no período de transição do Império para a República.

$O$ entendimento de que a educação seria de interesse público e de responsabilidade do Estado originou-se tão somente após os séculos XVI e XVII.

De absoluta relevância, a educação é um direito fundamental ao público infantil e adolescente na construção de sua autonomia e cidadania. 
O direito à educação tem sua natureza jurídica atrelada aos direitos fundamentais, humanos e naturais, os quais possuem suas semelhanças, todavia são tratados de forma muito diferenciada pela doutrina entre seus aspectos.

Direitos naturais dizem respeito à própria natureza humana e são universais., legítimos em todo o ordenamento jurídico, ao passo que os direitos fundamentais, segundo Canotilho (apud [5], p. 58), são direitos da personalidade, são os direitos do homem, jurídico-inconstitucionamente garantidos e limitados espacio-temporalmente.

$\mathrm{O}$ direito humano pode ser caracterizado como um direito de empoderamento, ao passo que a educação é o direito individual que permite a consolidação dos outros direitos humanos, pois o conhecimento adquirido no ensino formal e também informal acerca de seus direitos e também deveres, permite que o indivíduo acesse todos os outros direitos fundamentais.

Constata-se que a primeira menção constitucional expressa quanto ao planejamento educacional se deu na Constituição de 1934, em que o governo federal assume a tarefa de traçar as diretrizes sobre a educação nacional.

A educação possui total relevância ao ser humano, que o direito relacionado a ela é essencial, ou seja, como próprio direito à vida.

$O$ direito à educação distancia-se de ser avaliado tão somente como um direito social, tendo em conta que é intrínseco à vida da pessoa humana, pois está ligado às condições de uma vida digna em situações de sanidade física, psíquica e moral, bem como ao desenvolvimento da própria personalidade.

A personalidade do ser humano tem direitos chamados essenciais que fazem parte do conceito de pessoa, como direito à vida, à honra, à liberdade, etc. Logo, o direito à educação está totalmente incorporado ao direito à vida.

Portanto, essencial que se promova a conscientização da obrigação da família, Estado e da sociedade para crescimento do potencial humano por meio da educação ( [5] p.86), uma vez que os direitos da personalidade resguardam a dignidade humana.

Não obstante, o movimento de democratização da informação é um aspecto fundamental para se chegar à cidadania, ( [3], p. 26).

A democracia, a partir da Constituição Federal de 1988, em que pese não tenha dado conta da resolução de todos os problemas de desigualdade social, ainda possibilita a garantia de uma cidadania plena, mesmo que a longo prazo. Pois, sem o sistema democrático, as possibilidades de usufruto da cidadania são mínimas.

A definição de cidadania perpassa por muitos sentidos, como a concepção de cidadania plena, segundo Candau ( [3], p. 26), trata-se do "respeito integral a todos os direitos da pessoa humana e à existência de condições materiais, sociais, políticas e culturais necessárias à sua efetivação".

Atualmente, verifica-se as políticas neoliberais estão internalizadas na sociedade, razão pela qual muitas vezes a popu- lação opta por afastar o Estado da promoção da cidadania e dos direitos humanos.

No entanto, inegável que ao longo do século XX, o direito à educação avançou de aspiração nobre, tornando-se exigência legal do cidadão.

\section{CONSIDERAÇÕES FINAIS}

Estamos em permanente construção da história. Ainda há muito a que ser feito pelo Estado, pelas famílias, pelos sistemas de educação e pela sociedade para que crianças e adolescentes sejam efetivamente protegidos e tenham seus direitos garantidos.

Temos, a título de exemplo, que ainda os debates sobre redução da maioridade penal é tema latente na sociedade, por ser argumento político sobre questões de segurança pública.

Todavia, se há anos atrás, era preciso afirmar a criança como incapaz na incompletude de seu desenvolvimento, como requisito prévio para outorgar-lhe proteção, atualmente há quem pretenda declarar prematuramente a sua capacidade para o fim de promover a segregação.

Contudo, temos avanços sociais, políticos e educacionais para a promoção dos direitos das crianças e adolescentes.

A transformação da cultura por meio da educação em direitos humanos é apta para o desafio aos avanços do reconhecimento da subjetividade de crianças e adolescentes. Em que pese a realidade ainda não esteja igualmente nivelada às leis existentes, é incontestável que a legislação está contribuindo para a construção histórica, visto que o Brasil ostenta complexo de leis que podem viabilizar uma vida digna para crianças e adolescentes.

\section{Referências}

[1] Assembleia Geral da ONU. (1948). Declaração Universal dos Direitos Humanos. (217 [III] A). Paris

[2] BELLI, Benoni, A politização dos direitos humanos. 1 ed. São Paulo: Perspectiva, 2009. $280 \mathrm{p}$

[3] CANDAU, Vera Maria; SACAVINO, Susana. Educação em direitos humanos: temas, questões e propostas. Rio de Janeiro: DP ET ALII, 2008. 165

[4] CARBONARI, Paulo César. Sujeito de Direitos Humano: questões abertas e em construção. In: SILVEIRA, Rosa Maria Godoy, et al. Educação em Direitos Humanos: Fundamentos Teórico-metodológicos. João Pessoa: Editora Universitária, 2007. 511 p.

[5] NAÇÕES UNIDAS BRASIL. A Declaração Universal dos Direitos Humanos. Disponível em: nacoesunidas.org/direitoshumanos/declaracao. Acesso em: 23 mai. 2019.

[6] MARTINS, Rosilene Maria Solon Fernandes. Direito à educação: aspectos legais e constitucionais. Rio de Janeiro: Letra legal, 2004. 277 p.

[7] BRASIL. Constituição (1988). Constituição [da] República Federativa do Brasil. Brasília: Senado Federal, 1988. 


\section{IHANDARA PROENÇA LIMA}

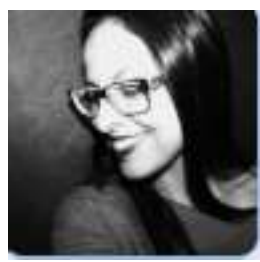

Advogada inscrita na OAB/PR sob $\mathrm{n}^{\circ} 58.260$, membro integrante da Comissão de Direito Sistêmico da OAB/PR. Mestranda em Direitos Humanos e Políticas Públicas pela PUCPR (2019). Possui graduação em Direito pela Pontifícia Universidade Católica do Paraná (2010), especialização em Direito Contemporâneo com Ênfase em Direito Público pela Universidade Positivo (2012) e especialização em Direito Processual Civil pela Uninter (2015). Tem experiência na área de Direito, com ênfase em Direito Civil, atuando principalmente nos seguintes temas: direito de família, direito sistêmico, constelação familiar, ciência da religiâo, conflito e fenomenologia.

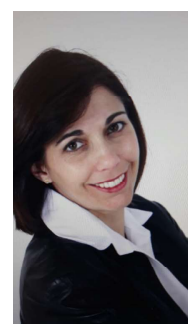

MIRIAN CELIA CASTELLAIN GUEBERT

Possui graduação em Pedagogia pela Universidade Federal do Paraná (1994), Especialização em Educação Especial ênfase em Condutas Típicas pela Universidade Tuiuti do Paraná(1996), Especialização em Educação Especial com ênfase em Política Públicas pela Universidade Federal do Mato Grosso do Sul(1998), mestrado em Engenharia de Produção pela Universidade Federal de Santa Catarina (2002), doutora em Educação, História, Política, Sociedade pela Pontifícia Universidade Católica de São Paulo (2013). Atualmente professora do Programa de Pós-graduação em Direitos Humanos e Políticas Públicas na Pontifícia Universidade Católica do Paraná. Professora convidada da Universidade Católica de Moçambique, no Doutorado de Humanidade. Tem experiência na área de Educação Especial, Educação Superior, atuando principalmente nos seguintes temas: gestão educacional, processo de ensino aprendizagem, competências profissionais, inclusão escolar, formação de professores, politicas públicas direitos humanos e ação docente. 